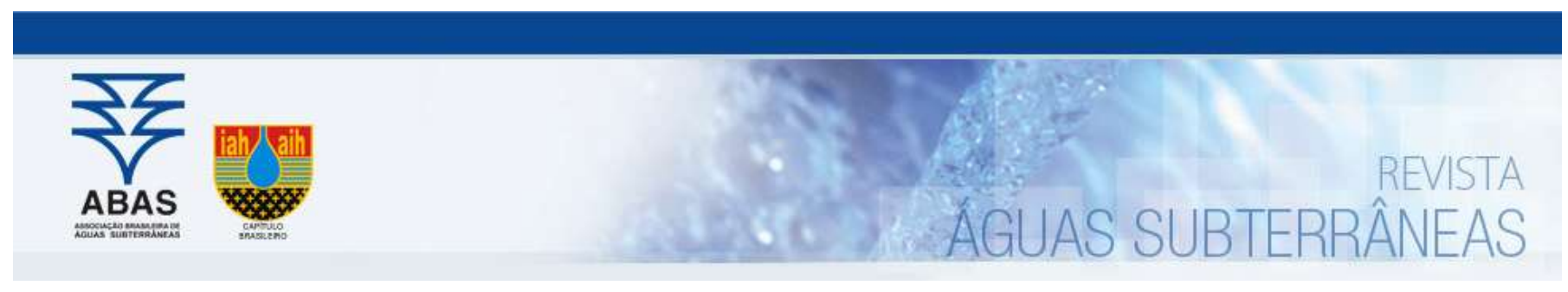

Artigos

\title{
Balanço patrimonial dos recursos hídricos: a situação das regiões hidrográficas do Brasil
}

\section{Accounting balance of water resources: the situation of the hydrographic regions of Brazil}

\author{
Jozenei Silva Pereira ${ }^{\boxplus}$ \\ 1 Universidade Estadual de Feira de Santana (UEFS), Feira de Santana, Bahia.
}

$\triangle$ ispconsultoria@hotmail.com

Palavras-chave:

Recurso Hídrico.

Contabilidade Ambiental.

Região Hidrográfica.

\section{Keywords: \\ Water resource. \\ Environmental Accounting. \\ Hydrographic Region.}

Revisado por pares.

Recebido em: 05/07/2018.

Aprovado em: 09/02/2019.

\begin{abstract}
Resumo
O objetivo da pesquisa é demonstrar, por meio do Balanço Patrimonial dos Recursos Hídrico, a situação sobre o consumo de recursos hídricos nas Regiões Hidrográficas do Brasil. Este estudo justifica-se pela relevância das informações geradas pela Contabilidade que contribuirão para a tomada de decisões dos gestores dos recursos hídricos, a importância de como as nações irão cuidar desses recursos nas próximas décadas e a continuidade de trabalhos acadêmicos que complementem para o avanco das ciências voltadas para o Meio Ambiente. Em termos metodológicos, esta pesquisa é de natureza empírica e exploratória. Para este fim, utilizou-se a tecnologia contábil denominada Balanço Patrimonial Hídrico, como segue: o Ativo Ambiental Hídrico é apurado com base no produto interno bruto da região; o Patrimônio Líquido Ambiental Hídrico é apurado pelo saldo residual das reservas hídricas estimadas e o Passivo Ambiental Hídrico é apurado por equivalência contábil por meio da Equação Fundamental da Contabilidade. Os resultados confirmaram a heterogeneidade daquelas regiões, a exemplo da Região Hidrográfica Amazônica que possui a maior reserva hídrica do país e o segundo menor consumo de água per capita, resultando em superávit patrimonial hídrico de US\$3.144,37 e a Região Hidrográfica Tocantins-Araguaia, mesmo obtendo a segunda colocação em termos de grande volume de reserva hídrica, no entanto, encontra-se na terceira posição em termos de elevação no consumo de água, resultando um déficit patrimonial hídrico de US\$212,32.
\end{abstract}

Abstract

The objective of the research is to demonstrate, through the Balance Sheet of Water Resources, the situation on the consumption of water resources in the Hydrographic Regions of Brazil. This study is justified by the relevance of the information generated by the Accounting that will contribute to the decision-making of water resources managers, the importance of how nations will take care of these resources in the next decades and the continuity of academic works that complement to advance the sciences focused on the Environment. In methodological terms, this research is empirical and exploratory. For this purpose, the accounting technology called the Balance Sheet was used as follows: the Environmental Water Asset is calculated based on the gross domestic product of the region; the Net Environmental Equity is determined by the residual balance of the estimated water reserves and the Environmental Water Portfolio is determined by accounting equivalence through the Fundamental Accounting Equation. The results confirmed the heterogeneity of these regions, such as the Amazon Hydrographic Region, which has the largest water reserve in the country and the second lowest per capita water consumption, resulting in a net capital surplus of US\$3,144.37 and the Tocantins-Araguaia Hydrographic Region, even obtaining the second place in terms of large volume of water reserve, however, was in the third position in terms of increase in water consumption, resulting in a water deficit of US\$212.32.

DOI: http:/dx.doi.org/10.14295/ras.v33i1.29177

\section{INTRODUÇÃO}

O crescimento da população, a expansão da atividade industrial e a alta demanda por recursos hídricos contribuíram para o aumento do consumo de água mundial. 0 manejo inadequado, provenientes da demanda maior que a oferta deste recurso ambiental, provocou incertezas e condições de riscos ao futuro desses recursos naturais. Estes fatos relatados pela União das Nações Unidas (ONU) têm sido motivos de preocupações para pesquisadores ambientais em varias partes do mundo (UNESCO, 2012).

A sexta edição do Relatório Mundial das Nações Unidas sobre o
Desenvolvimento dos Recursos Hídricos, publicado em março de 2015, prevê um déficit hídrico mundial de 40\% para ano de 2030 e um aumento de $55 \%$ da demanda hídrica para o ano de 2050. Portanto, recomenda-se implementar mudanças na atual gestão desses recursos para evitar a concretização desses resultados negativos (UNESCO, 2015).

O Brasil possui reservas hídricas bastante satisfatórias. No entanto, em algumas Regiões Hidrográficas, essas reservas são extensas, a exemplo da Região Hidrográfica Amazônica, com 78,7\% da disponibilidade hídrica do país e uma população de 9,7 milhões de habitantes; em outras regiões, a reserva de água potável é bastan- 
te reduzida, é o caso da Região Hidrográfica do Atlântico Nordeste Oriental, que possui $0,2 \%$ de recursos hídricos do total das reservas existentes no Brasil, para uma população de 24,1 milhões de habitantes (ANA, 2013).

Nesse contexto de demanda/reserva hídrica, compreende-se que relatórios sobre a atual situação da água podem auxiliar aos gestores na tomada de decisões. Porém, estes gestores precisam tomar medidas imediatas para que a disponibilidade dos recursos hídricos não seja comprometida.

Para Alfieri e Matteo (2004, p. 353), “a contabilidade de recursos hídricos compreende as contas de estoque e fluxo, em termos físicos, monetários e qualitativos". A contabilização desses recursos pode produzir indicadores reunidos em sistema contábil.

Percebe-se que, nas pesquisas no campo da Ciência Contábil voltada para o Meio Ambiente, evidencia-se, para a sociedade, acadêmicos e demais interessados, que métodos estão sendo implementados para relatar por meio de tecnologias da contabilidade que possam contribuir para tomada de decisões dos gestores dos recursos ambientais.

Diante do exposto, a problemática do estudo versou no seguinte questionamento: É possível gerar informações sobre os Recursos Hídricos partindo-se ferramentas da Contabilidade? Destarte, a pesquisa é de natureza empírica e exploratória e objetivou-se em demonstrar por meio de tecnologias da Contabilidade o Balanço Patrimonial Hídricos de Regiões Hidrográficas situadas no território brasileiro.

O trabalho justifica-se pela relevância das informações geradas pela Contabilidade e a importância de como o Brasil irá cuidar dos recursos hídricos nas próximas décadas, servindo ainda como referência para a continuidade de trabalhos acadêmicos que complementem para o avanço das ciências voltadas para o Meio Ambiente. Ressalta-se que até a data de construção desse trabalho, referências bibliográficas são escassas em periódicos brasileiros, no que se refere a assuntos relacionados à contabilização de recursos hídricos.

\section{RECURSOS HÍDRICOS}

A ONU iniciou em 2003 o Relatório Mundial da Nações Unidas Sobre o Desenvolvimento dos Recursos Hídricos (World Water Development Report - WWDR), com objetivo de demonstrar a situação da água potável mundial e, em consequência disto, proporcionar discussões sobre providencias a serem tomadas pelos gestores dos recursos hídricos (UNESCO, 2003).

A atual situação da reserva natural de água potável do mundo conduz a reflexões sobre o uso inadequado deste recurso. Philippi Jr (2005) salienta que, durante muitos séculos, este recurso foi considerado de quantidade infinita à disposição do homem, por se tratar, na época ,de recurso natural renovável.

Pesquisa realizada por Richey et al (2015) constatou que, entre os trinta e sete maiores aquíferos subterrâneos do mundo, analisados entre 2003 a 2013, vinte e um destes aquíferos resultaram em déficit hídrico (retirada de água maior do que a entrada de água no aquífero) e oito destes foram considerados com quase nenhuma reposição natural para compensar o uso. 0 estudo revelou, também, que o Sistema Aquífero Árabe (localizado abaixo do lêmen e da Arábia Saudita, fonte de água para mais de 60 milhões de pessoas) resultou no déficit hídrico mais crítico do mundo.

O Brasil possui reservas hídricas de extensa proporção, em média $12 \%$ do total existente no mundo, superando até alguns continentes mundiais, a exemplo da Oceania, que detém 6\%, Europa com $7 \%$, e África que apresenta 9\% (MARCONI; FERREIRA, 2009). No entanto, em algumas Regiões Hidrográficas $(\mathrm{RH})$ brasileiras as reserva de água potável são extremamente baixas, a exemplo da $\mathrm{RH}$ do Atlântico Nordeste Oriental, que possui uma reserva de 0,2\%, considerada a menor disponibilidade hídrica comparada com as demais RH existentes no país (ANA, 2013).

O Brasil estava subdividido em oito Bacias Hidrográficas. Porém, em 2003, após publicação da Resolução n ${ }^{\circ} 32$ do Conselho Nacional de Recursos Hídricos (CNRH), o termo bacia passou a ser denominado região, passando para 12 Regiões Hidrográficas (PAZ, 2004).

Uma Bacia Hidrográfica (BH) corresponde a “[...] área de captação natural da água de precipitação que faz convergir os escoamentos para um único ponto de saída" e "[...] As RHs foram traçadas com base nas bacias hidrográficas, mas respeitando alguns limites geopolíticos" (PAZ, 2004, p. 21).

A Tabela 1 apresenta a distribuição dos recursos hídricos do Brasil em $\mathrm{RH}$, em metros cúbicos, por habitante e por ano, suas respectivas populações e reservas hídricas.

A RH Amazônica abrange os Estados do Acre, Amazonas, Rondônia, Roraima, Amapá, Pará e Mato Grosso. Esta RH destaca-se por possuir $78,7 \%$ de reserva hídrica do país, para uma população equivalente a $5,1 \%$ do total nacional. Por sua vez, a RH Atlântico NE Oriental (Piauí, Ceará, Rio Grande do Norte, Paraíba, Pernambuco e Alagoas) dispõe de $0,2 \%$ de água potável e uma população correspondente a 12,6\% dos habitantes do Brasil (ANA, 2015b). Esta disparidade em reserva hídrica decorre por encontrar-se nesta região grande parte do semiárido nordestino, área bastante explorada pelo alto índice de evapotranspiração, entre outros casos, provocando um déficit hídrico bastante elevado (ANA, 2015b).

Os dados apresentados da RH Paraná (São Paulo, Paraná, Mato Grosso do Sul, Minas Gerais, Goiás, Santa Catarina e Distrito Federal) ratificam um montante populacional equivalente a $32,1 \%$, para uma reserva hídrica correspondente a 7,2\%. No entanto, A RH Tocantins-Araguaia (Goiás, Tocantins, Pará, Maranhão, Mato Grosso e Distrito Federal) dispõe de uma população de 4,5\%, com reserva hídrica proporcional a 5,9\% do país (ANA, 2015c).

A RH Atlântico NE Oriental, RH São Francisco (Bahia, Minas Gerais, Pernambuco, Alagoas, Sergipe, Goiás, e Distrito Federal), RH Atlântico Leste (Bahia, Minas Gerais, Sergipe e Espírito Santo) e RH Parnaíba (Piauí e parte do Maranhão e Ceará) juntas perfazem um total de $30,2 \%$ da população brasileira, totalizam em reserva hídrica $3,4 \%$ da capacidade nacional. 
Tabela 1 - Dados das Regiões Hidrográfica do Brasil, 2010.

\begin{tabular}{lrr}
\multicolumn{1}{c}{ Regiões Hidrográficas } & \multicolumn{1}{c}{ População } & Reserva Hídrica em metros cúbicos per capita por ano \\
\hline Amazônica & 9.694 .728 & $262.919,06$ \\
Tocantins-Araguaia & 8.572 .716 & $22.259,50$ \\
Atlântico NE Ocidental & 6.244 .419 & $2.542,31$ \\
Parnaíba & 4.152 .865 & $4.601,84$ \\
Atlântico NE Oriental & 24.077 .328 & 232,49 \\
São Francisco & 14.289 .953 & $4.945,58$ \\
Atlântico Leste & 15.066 .543 & 816,31 \\
Atlântico Sudeste & 28.236 .436 & $1.441,86$ \\
Atlântico Sul & 13.396 .180 & $2.023,12$ \\
Paraná & 61.290 .272 & $3.803,96$ \\
Uruguai & 3.922 .873 & $7.757,64$ \\
Paraguai & 2.165 .938 & $20.369,40$ \\
Brasil & 191.110 .251 & $16.947,39$ \\
\hline Fonte:
\end{tabular}

Fonte: adaptada ANA (2013)

A RH do Atlântico Sudeste (Minas Gerais, Espírito Santo, Rio de Janeiro, São Paulo e Paraná) e RH do Atlântico Sul (São Paulo, Paraná, Santa Catarina e Rio Grande do Sul) abarcam 21,8\% da população brasileira, para reservas de água compreendidas em $2,1 \%$ existente no país.

A RH Atlântico NE Ocidental (Maranhão e pequena parcela do Pará), constitui-se de 3,3\% da população do país, para uma reserva hídrica de 0,5\%. Por fim, a RH Uruguai (porções dos estados do Rio Grande do Sul e de Santa Catarina) e Paraguai (porções dos estados do Mato Grosso e Mato Grosso do Sul), totalizam 3,2\% da população brasileira, consideradas menores em número de habitantes, em relação às demais regiões, para reserva hídrica de $2,3 \%$.

\section{A CONTABILIDADE E OS RECURSOS HÍDRICOS}

A Contabilidade é ciência social aplicada e consiste em gerar informações sobre o patrimônio das diversas células sociais. Esta ciência evolui e, de acordo com a necessidade de preservação ambiental, desenvolve a Contabilidade Ambiental para mensurar, evidenciar e demonstrar por meio de ferramentas contábeis, informações sobre atos e fatos que afetam o meio ambiente.

Na interpretação de Mattos (2003), a bacia hidrográfica compreende-se em uma entidade e nela aplica-se os conceitos tradicionais da contabilidade, adaptado para os recursos hídricos. 0 autor atribuiu aos ativos, como sendo bens adquiridos por uma Unidade de Gestão que propicie a preservação do seu corpo hídrico. E ao passivo, gastos com recursos hídricos ocorridos em função de obrigações assumidas pelos usuários desses recursos.

Os estudos concretizados por Carvalho (2008) sobre a contabilização dos recursos hídricos objetivou em identificar se os agricultores do sudoeste goiano atribuíam valores monetários às suas propriedades rurais pela disponibilidade desses recursos, que os permitiam a utilização destes recursos naturais na irrigação de suas lavouras. Ele apresentou discussões e classificações para identificação e contabilização dos recursos hídricos argumentando que estariam sendo classificados de forma equivocada no ativo imobilizado e que deveriam ser contabilizados no ativo intangível.

O profissional da contabilidade desempenha um papel fundamen- tal na disponibilização de informação sobre a água de forma transparente e responsável para garantir que as partes interessadas possam fazer julgamentos com conhecimento de causa $\mathrm{AH}-$ MAD et al, 2010). Os autores examinaram o estado atual da contabilidade da água pelas autoridades australianas e constataram que se faz necessário a disponibilização de informações por parte destas autoridades, em termos de quantidade disponivel, capacidade de armazenamento, qualidade e valoração da água.

Pesquisa realizada por Jia et al (2017) destacou sobre a aplicação do Sistema de Contabilidade Ambiental e Econômica da Água (Environmental and Economic Accounting for Water - SSEAW) na China, país com intensa escassez de água. Neste trabalho, autores implementam que a contabilidade dos recursos hídricos visaria avaliar objetivamente a contribuição da água para o desenvolvimento econômico e social e os efeitos negativos que a utilização excessiva da desse recurso natural pode causar a sociedade local com proporções globais.

Desta forma, percebe-se a dedicação em pesquisas científicas, cujos temas contextualizam meio ambiente como uma entidade, sendo esta denominada patrimônio ambiental e evidenciada por meio de Demonstração Contábil.

\section{METODOLOGIA}

Esta pesquisa é de natureza empírica e exploratória, visando demonstrar por meio de tecnologias da Contabilidade o Balanço Patrimonial Hídrico proveniente das Regiões Hidrográficas do Brasil. Para tanto, recorreu-se ao estudo bibliográfico de artigos, dissertações, livros, publicações da ANA e dados do número de habitantes brasileiros, sendo estes encontrados no acervo do Instituto Brasileiro de Geografia e Estatística (IBGE).

O Balanço Patrimonial dos Recursos Hídricos está subdividido em Ativo Ambiental Hídrico (representa a parcela de recurso hídrico que o habitante adquiriu para seu sustento); Patrimônio Líquido Ambiental Hídrico (corresponde ao saldo residual de reserva de água disponível para o habitante) e Passivo Ambiental Hídrico (compreendido em saldo de obrigação de cada habitante em relação ao seu sustento e a preservação ambiental).

Para mensurar os ativos, passivos e o patrimônio líquido deste 
trabalho, utilizou-se o respectivo método contábil:

a) Ativo Ambiental Hídrico (AAH): é apurado pelo PIB da RH per capita equivalente em dólares (US\$), e ajustado pela depreciação ambiental hídrica (DAH) calculada com base num fator de depreciação hídrica (FDH) estabelecido neste trabalho como o coeficiente entre o consumo médio de água per capita da RH dividido pelo seu consumo equivalente estabelecido pela ONU. Como justificativa para esse ajuste no ativo, considerou-se a orientação da ONU de 40,15 $\mathrm{m}^{3}$ de água per capita e por ano. Essa DAH resultará num ajuste negativo para as regiões que consumirem acima do proposto pela ONU e num ajuste positivo para as regiões com resultado de consumo abaixo do recomendado pela ONU. b) Patrimônio Líquido Ambiental Hídrico (PLAH): é apurado pelo saldo residual de reservas de águas, per capita e em metros cúbicos $\left(m^{3}\right)$, apurado entre a reserva de água disponível estimada para a região, diminuído do consumo médio estimado até o ano de 2050, e valorizado pelo preço do serviço ambiental determinado por órgão competente, no caso deste trabalho o estabelecido pela Lei Federal 9.433/1997 (que institui a Política Nacional de Recursos Hídricos) e regulamentado pelo Conselho Nacional dos Recursos Hídricos (dois centavos por metro cúbico).

c) Passivo Ambiental Hídrico (PAH): é apurado por equivalência contábil por meio da Equação Fundamental da Contabilidade (passivo = ativo - patrimônio líquido).

Segue a Figura 1 representando o modelo do balanço patrimonial dos recursos hídricos disposto nesta pesquisa.

Figura1 - Esboço do modelo "Balanço Patrimonial Ambiental Hídrico"

\begin{tabular}{||c||c||}
\hline ATIVO & PASSIVO \\
Ativo Ambiental Hídrico & $\begin{array}{c}\text { Apurado por equivalência contábil por meio da } \\
\text { equação fundamental da contabilidade }\end{array}$ \\
$\begin{array}{c}\text { apurado com base no produto interno bruto (PIB) } \\
\text { da região, per capita, equivalente em dólares } \\
\text { (US\$), e ajustado pela depreciação ambiental } \\
\text { hídrica }\end{array}$ & SaTRIMÔNIO LíQUIDO \\
\cline { 2 - 2 } & \\
&
\end{tabular}

Fonte: Pereira; Kassai e Ramos (2015)

\section{ANÁLISE DOS RESULTADOS}

\subsection{Ativo Ambiental Hídrico}

As regiões hidrográficas brasileiras estão subdivididas em 12 unidades, conforme Resolução $n^{\circ} 32$, publicada em outu- bro de 2003 pelo CNRH. Estas regiões são monitoradas e fiscalizadas pela ANA. Para fins de mensuração dos ativos das demais regiões foi necessário recorrer ao IBGE e a ANA para coletar os dados necessários. Segue Tabela 2 que evidencia o PIB per capita anual, e o consumo de água per capita anual das demais regiões.

Tabela 2 - PIB per capita e consumo de água per capita das Regiões Hidrográfica do Brasil (ANA, 2010).

\begin{tabular}{lrr}
\hline \multicolumn{1}{c}{ Regiões Hidrográficas } & PIB per capita anual em dólares (US\$) & Consumo de água per capita m $/$ ano \\
\hline Amazônica & $8.676,03$ & 256,33 \\
Tocantins-Araguaia & $7.431,40$ & 498,82 \\
Atlântico NE Ocidental & $4.030,08$ & 119,69 \\
Parnaíba & $3.876,09$ & 386,52 \\
Atlântico NE Oriental & $6.129,93$ & 343,16 \\
São Francisco & $8.900,51$ & 615,27 \\
Atlântico Leste & $6.786,50$ & 235,06 \\
Atlântico Sudeste & $14.219,74$ & 238,67 \\
Atlântico Sul & $14.571,53$ & 695,40 \\
Paraná & $16.834,42$ & 378,70 \\
Uruguai & $12.136,62$ & $1.249,26$ \\
Paraguai & $11.514,09$ & 436,80 \\
Brasil & $11.863,12$ & 391,51 \\
\hline
\end{tabular}

Fonte: adaptada IBGE (2010); ANA (2013) 
A RH Uruguai destaca-se pelo maior consumo de água por habitante, comparado com as demais regiões e o Brasil. Em termos percentuais, em relação ao Brasil, compreende em mais de $219 \%$. Esta região é a segunda menor em termos de número de habitantes e a quinta menor em relação à reserva hídrica.

A RH Amazônica apresenta-se com segundo menor consumo de água per capita, o equivalente a $34 \%$ em relação ao Brasil e o quarto menor PIB per capita comparada com o Brasil e as demais regiões. Porém, nesta região encontra-se a maior reserva de água existente no país.

O consumo de água per capita da RH Paraguai é o quinto maior entre as regiões. No entanto, esta região possui a menor população em ralação às demais e ocupa a sexta colocação em termos de reserva hídrica.

As regiões que complementam grande parte do semiárido nordestino, sejam elas: RH Atlântico NE Ocidental; RH São Francisco; RH Atlântico Leste e RH Parnaíba, ocupam uns dos menores PIB's entre as demais regiões. Destaca-se a RH São Francisco que pos- sui o terceiro lugar de maior consumo per capita de água e a quarta colocação entre as menores reservas hídricas.

No que se refere ao consumo de água por habitante, a Organização Mundial de Saúde (OMS) recomenda 110 litros diários o ideal para um indivíduo satisfazer suas necessidades vitais (OMS, 2003), totalizando $40,15 \mathrm{~m}^{3}$ por ano. No entanto, os habitantes situados nas Regiões Hidrográficas do Brasil estão fora desta realidade, pois os consumos de água per capita nestas regiões excederam ao da recomendação. Vale ressaltar que este excesso é considerado como desperdício.

Para a mensuração do ativo, disposto no presente trabalho, considerou-se a conversão do PIB por habitante equivalente de água, procedimento este que representa a parcela da população compreendida em valores monetários dos recursos hídricos que cada habitante adquiriu para o seu sustento.

Para o cálculo da representação do ativo dos recursos hídricos proveniente do resultado do PIB por habitante dividido pelo consumo médio de água por habitante, seguem as fórmulas:

Figura 2 - Formula para Mensurar o AAH
$\begin{aligned} & \text { AAH }= \\ & \text { AAH ajustado }=\text { AAH } \div \text { FDH } \\ & \text { FDH }=\quad \text { Consumo per capita anual } \\ & \frac{\text { Consumo per capita anual (ONU) }}{\text { Consula anual }}\end{aligned}$

Segue Tabela 3 demonstrando o Ativo Ambientai Hídricos (AAH), Fator de Depreciação Hídrica (FDH) e a Depreciação Hídrica (DH) das Regiões Hidrográficas (RH) e do Brasil do ano de 2010, convertidos em dólares americanos (US\$) pelo Banco Central do Brasil (BC), pela cotação comercial de 31/12/2010. Vale ressaltar que não foram apresentados anos posteriores a 2010, devido a não disponibilidade dos dados daqueles anos referente ao número de habitantes e consumo per capita das RH. Dados estes sob a competência de divulgação por parte do IBGE e ANA.

Tabela 3 - Composição do Ativo das Regiões Hidrográficas do Brasil, 2010.

\begin{tabular}{lrrrr}
\hline \multicolumn{1}{c}{ Regiões Hidrográficas } & AAH em US & \multicolumn{1}{c}{ FDH } & Depreciação Hídrica em US\$ & AAH em US\$ menos DH \\
\hline Amazônica & 33,85 & 6,38 & 28,55 & 5,30 \\
Tocantins-Araguaia & 14,90 & 12,42 & 13,70 & 1,20 \\
Atlântico NE Ocidental & 33,67 & 2,98 & 22,38 & 11,29 \\
Parnaíba & 10,03 & 9,63 & 8,99 & 1,04 \\
Atlântico NE Oriental & 17,86 & 8,55 & 15,77 & 2,09 \\
São Francisco & 14,47 & 15,32 & 13,52 & 0,94 \\
Atlântico Leste & 28,87 & 5,85 & 23,94 & 4,93 \\
Atlântico Sudeste & 59,58 & 5,94 & 49,56 & 10,02 \\
Atlântico Sul & 20,95 & 17,32 & 19,74 & 1,21 \\
Paraná & 44,45 & 9,43 & 39,74 & 4,71 \\
Uruguai & 9,72 & 31,11 & 9,40 & 0,31 \\
Paraguai & 26,36 & 10,88 & 23,94 & 2,42 \\
Brasil & 30,30 & 9,75 & 27,19 & 3,11 \\
\hline
\end{tabular}


O FDH da RH Uruguai destacou-se por ser o mais elevado entre todas as regiões do Brasil, este fato corresponde ao grande volume de água consumida nesta região. Assim, compreendendo um ajuste negativo para com o AAH, devido ao consumo de água por habitante ser maior que o consumo recomendado pela ONU. Destaca-se a DH da RH Uruguai que concentrou quase a totalidade do AAH desta região.

A DH da RH Atlântico Sul consumiu em média 94\% do seu AAH, na sequencia, encontram-se a DH da RH São Francisco com 93\%, a $\mathrm{DH}$ da RH Tocantis-Araguaia com $92 \%$ e a $\mathrm{DH}$ da RH Paraguai e com $90 \%$. Vale um destaque para a $\mathrm{DH}$ da $\mathrm{RH}$ do Atlântico NE Ocidental com $66 \%$ do seu AAH, esta $\mathrm{DH}$ considerada a menor entre todas as regiões inclusive o Brasil.

\subsection{Patrimônio Líquido Ambiental Hídrico}

O patrimônio líquido disposto neste trabalho representa o saldo residual de reserva de água per capita e em metros cúbicos, apurado entre a reserva de água per capita para cada $\mathrm{RH}$, diminuído do consumo médio estimado até o ano de 2050, e valorizado pelo preço do serviço ambiental por órgão competente estabelecido pela Lei 9.433 de 1997 e regulamentado por resolução proferida pelo Conselho Nacional dos Recursos Hídricos (CNRH).

Neste estudo o preço do serviço ambiental pela capitação de água bruta por metro cúbico está compreendido em dois centavos (média dos valores cobrados pelo uso da água de domínio da União). Vale ressaltar que até a presente data estão sendo cobrados serviços ambientais pelo uso dos recursos hídricos da Bacia do Rio Paraíba do Sul; Bacias dos Rios Piracicaba, Capivari e Jundiaí; Bacia do Rio São Francisco e Bacia do Rio Doce (ANA, 2013).

A Lei da Política Nacional dos Recursos Hídricos, em seu artigo 19, destaca alguns objetivos compreendidos pela cobrança do uso dos recursos hídricos, tais como:

I - reconhecer a água como bem econômico e dar ao usuário uma indicação de seu real valor; II - incentivar a racionalização do uso da água; III - obter recursos financeiros para o financiamento dos programas e intervenções contemplados nos planos de recursos hídricos. (BRASIL, 1997. p. 4)

A projeção do consumo de água para o ano de 2050 com objetivo de mensurar o patrimônio liquida da região estudada, foi feita por método de progressão geométrico, representado pela formula:

$$
\mathrm{Pp}=(\mathrm{Tx}+1)^{\mathrm{n}} \times \mathrm{Pa}
$$

Onde,

$\mathrm{Pp}=$ Período projetado

$\mathrm{Tx}=$ Taxa de crescimento

$\mathrm{n}=$ número de tempo a ser projetado

$\mathrm{Pa}=$ Período atual

Para o calculo da taxa de crescimento, utilizou-se a formula:

Onde,

$$
\mathrm{Tx}=(\mathrm{Pa} / \mathrm{Pi})^{1 / \mathrm{n}}-1
$$

$\mathrm{Tx}=$ Taxa de crescimento

$\mathrm{Pa}=$ Período atual

$\mathrm{Pi}=$ Período inicial

$\mathrm{n}=$ número de tempo

Segue Tabela 4 especificando o PLAH das Regiões Hidrográficas e do Brasil com valores convertidos pelo Banco Central do Brasil (BC) em dólares americanos, pela cotação de 31/12/2010.

\begin{tabular}{|c|c|c|c|c|}
\hline Regiões Hidrográficas & $\begin{array}{l}\text { Projeção de Consumo } \\
\text { per capita de água em } \\
\mathrm{m}^{3} / \text { ano }\end{array}$ & $\begin{array}{l}\text { Saldo Residual de } \\
\text { reserva de água em } \\
\mathrm{m}^{3} / \text { ano }\end{array}$ & $\begin{array}{c}\text { Serviço } \\
\text { Ambiental em } \\
\mathrm{R} \$\end{array}$ & PLAH em US\$ \\
\hline Amazônica & 961,2 & $261.957,90$ & 0,02 & $3.144,37$ \\
\hline Tocantins-Araguaia & $39.948,2$ & $17.688,67$ & 0,02 & $(212,32)$ \\
\hline Atlântico NE Ocidental & 547,0 & $1.995,29$ & 0,02 & 23,95 \\
\hline Parnaíba & $2.657,3$ & $1.944,55$ & 0,02 & 23,34 \\
\hline Atlântico NE Oriental & $1.096,1$ & 863,56 & 0,02 & $(10,37)$ \\
\hline São Francisco & $19.670,9$ & $14.725,27$ & 0,02 & $(176,75)$ \\
\hline Atlântico Leste & $1.178,9$ & 362,56 & 0,02 & $(4,35)$ \\
\hline Atlântico Sudeste & 566,8 & 875,04 & 0,02 & 10,50 \\
\hline Atlântico Sul & $1.222,0$ & 801,12 & 0,02 & 9,62 \\
\hline Paraná & $9.389,8$ & $5.585,81$ & 0,02 & $(67,05)$ \\
\hline Uruguai & $1.806,3$ & $5.951,34$ & 0,02 & 71,44 \\
\hline Paraguai & 499,7 & $19.869,74$ & 0,02 & 238,50 \\
\hline Brasil & $2.968,2$ & $13.979,15$ & 0,02 & 167,80 \\
\hline
\end{tabular}

Tabela 4 - Composição do PLAH das Regiões Hidrográficas do Brasil e a média nacional, 2010.

Fonte: 0 autor

O PLAH da RH Amazônica resultou num superávit hídrico bastante elevado, conforme disposto na Tabela 4, devido ao imenso valor do saldo residual, após a diminuição do consumo per capita de água. Porém, o PLAH da RH Tocantins-Araguaia, RH NE Oriental, RH São Francisco, RH Atlântico Leste e da RH Paraná concretizouse em déficit hídrico. Este fato resultou em consequência do histórico de consumo intenso de água per capita entre os anos de
2006 a 2010 (ANA, 2013).

\subsection{Passivo Ambiental Hídrico (PAH)}

O PAH das Regiões Hidrográficas e do Brasil corresponde à obrigação em valor monetário que cada habitante adquiriu, pelo uso dos recursos hídricos e a responsabilidade daquele em reaver para o 
meio ambiente contribuições necessárias para preservação ambiental. Este PAH foi apurado por equivalência contábil por meio da Equação Fundamental da Contabilidade (PAH = AAH - PLAH). Na Figura 3, está representado o Balanço Patrimonial Ambiental Hí- drico (BPAH) das Regiões Hidrográficas e do Brasil em US\$, convertido em dólar americano pelo Banco Central do Brasil (cotação de 31/12/2010).

Figura 3 -Balanço Patrimonial Ambiental Hídrico das Regiões Hidrográficas e do Brasil, 2010

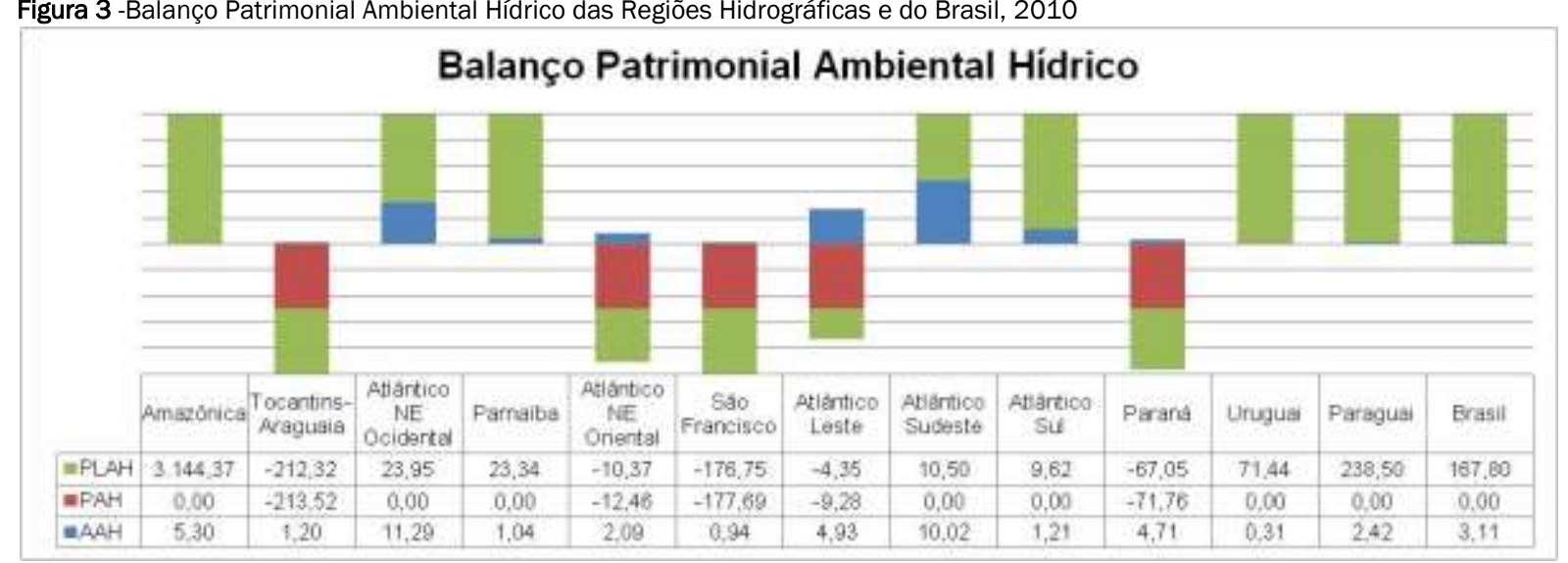

O BPAH demonstrado na Figura 3 resultou em superávit hídrico (resultado positivo do PLAH) nas regiões de saldo residual satisfatório, em alguns casos estes saldos resultaram em PLAH tão elevado que absorveram o PAH. É o caso da RH Amazônica, RH Atlântico NE Ocidental, RH Parnaíba, RH Atlântico Sudeste, RH Atlântico Sul, RH Uruguai, RH Paraguai e o Brasil. Porém, algumas regiões obtiveram déficit hídrico (resultado negativo do PLAH), a exemplo da RH Tocantins Araguaia (US\$ -212,32), RH São Francisco (US\$ $176,75)$ por conta do elevado consumo de água per capita projetado para o ano de 2050, conforme disposto na Tabela 4.

\section{CONSIDERAÇÕES FINAIS}

Os gestores dos recursos hídricos devem revisar suas medidas para que possam tomar decisões ambientalmente sustentáveis. A utilização de demonstrações contábeis ambientais podem auxiliar esses gestores na tomada dessas decisões.

O Brasil possui reserva de água bastante satisfatória, porém a proporcionalidade destas reservas é bastante heterogênea nas $\mathrm{RH}$. Para tanto, a gestão brasileira da água precisa de mudanças imediatas, pois todas as regiões pesquisadas estão fora da realidade do consumo sustentável de 40,15 $\mathrm{m}^{3}$ de água per capita anual, inclusive o país como um todo, que apresentou 391,51 m³/ano per capita. A RH Atlântico NE Ocidental (119,69 m³/ano per capita), concentrou o menor consumo dentre as demais regiões. Porém, a RH Uruguai (1.249,26 m³/ano per capita) contraiu o maior consumo entre as regiões.

O objetivo da pesquisa foi alcançado ao propor o modelo de contabilização e elaboração do Balanço Patrimonial Ambiental das Regiões Hidrográficas do Brasil, com ativos avaliados pelo PIB per capita, o patrimônio líquido pelo saldo residual de recursos hídricos e o passivo como uma obrigação ambiental.

Os resultados evidenciaram superávit hídrico em algumas regiões, a exemplo da RH Amazônica, devido a sua reserva hídrica ultrapassar dos $78 \%$ das reservas existentes no país. Já o consumo de água projetado para o ano de 2050, disposto em algumas regiões resultou em déficit hídrico. É o caso da RH Tocantins-Araguaia que suas reservas de água não foram suficientes para cobrir as obriga- ções contraídas por cada habitante desta região, pelo consumo de água.

A contabilidade é vista como imprescindivel e contributiva na gestão dos recursos hídricos, pois possibilita maior conhecimento aos gestores e a sociedade sobre o controle do patrimônio ambiental. Sendo assim, o profissional contábil exerce sua função de responsabilidade socioambiental, informando à sociedade as mudanças e implicações que o uso desnecessário e desordenado dos recursos ambientais possa causar a vida da população local com proporções globais.

A falta de dados de anos posteriores a 2010 foi a grande dificuldade para concretização da pesquisa, devido a não disponibilização por parte da ANA e do IBGE desses dados até a data de encerramento deste estudo.

O estudo contribui para futuras pesquisas que demonstrem a importância da contabilidade para com os recursos hídricos, sendo estes recursos escassos e que precisam ser monitorados e fiscalizados não só pelos gestores, mas também pela sociedade em geral. Contudo, sugere-se a continuidade dos estudos com dados mais atualizados sobre a reserva e consumo de água dos estados brasileiros e demais países.

\section{REFERÊNCIAS}

ALFIERI, A.; MATTEO, I. D. Contas ambientais para recursos hídricos. In ROMEIRO, A. R. (Org.). Avaliação e contabilização de impactos ambientais. São Paulo: Unicamp, 2004.

AgENCIA NACIONAL DE ÁGUAS. Conjuntura dos Recursos Hídricos no Brasil. Brasília: ANA, 2013. Disponível em http://arquivos.ana.gov.br/institucional/spr/ conjuntura/webSite_relatorioConjuntura/projeto/index.html. Acesso em: $15 \mathrm{fev}$. 2015.

. Conjuntura dos recursos hídricos no brasil informe 2014. Brasília: ANA, 2015a. Disponivel em: http://conjuntura.ana.gov.br/docs/ conj2014_inf.pdf. Acesso em: 15 jun. 2015.

Conjuntura dos recursos hídricos no brasil informe 2014: encarte especial sobre a crise hídrica. Brasília: ANA, 2015b. Disponível em: http://conjuntura.ana. gov.br/docs/ conj2014_inf.pdf. Acesso em: 15 jun. 2015. 
- Conjuntura dos recursos hídricos no Brasil: regiões hidrográficas brasileiras edição especial. Brasília: ANA, 2015c. Disponível em: http://conjuntura. ana.gov.br/docs/conj2014_ inf.pdf. Acesso em: 15 jun. 2015.

AHMAD, R. A. R. Transparency and clarity of water accounting reporting. UNISA, $2010 . \quad$ Disponivel em: https://www.unisa.edu.au/Global/business/centres/ cags/docs/ apcea/APCEA_2010_16(4)_Ahmad_etal.pdf. Acesso em: 12 jun. 2018.

BORBA, N. Z. A Água como bem jurídico econômico. Temiminós Revista Científica. Rio de Janeiro: CNECRJ, 2015. Disponível em: http://www.cnecrj.com.

br/ojs/index.php/temiminos/article/view/121/85em. Acesso em: 09 jul. 2015.

BRASIL. Lei n. 9.433, de 8 de janeiro de 1997. Institui a política naciona de recursos hídricos, cria o sistema nacional de gerenciamento de recursos hídricos. Disponível em: http://www.planalto.gov.br/ccivil_03/LEIS/L9433.htm. Acesso em: 20 jun. 2015.

Lei n. 9.984, de 17 de junho, 2000. Dispõe sobre a criação da agência nacional de águas. Disponível em: http://www.planalto.gov.br/ccivil_03/LEIS/ L9984.htm. Acesso em: 20 jun. 2015.

Resolução n. 32, de 15 de outubro, 2003. Dispõe sobre a divisão das regiões hidrográficas do Brasil. Diário Oficial da União. Brasília, DF: Conselho Nacional de Recursos Hídricos. Disponível em: http://www.cnrh.gov.br/index.php? option=com _ do cman\&task=doc_download\&gid=74. Acesso em: 28 jun. 2015.

CARVALHO, A. M. R. de. Gestão dos recursos hídricos: estudo exploratório no estado de goiás e formulação de um modelo contábil. 2008. 210 p Tese de Doutorado em Ciências Ambientais, Universidade Federal de Goiás, Goiânia. Disponível em: https://ciamb.prpg.ufg.br/up/104/o/Tese_Ant_nio_Manoel_R._

de_Carvalho_-_C._Ambientais_2008.pdf. Acesso em: 28 junho de 2015.

ECKERT, A. et al. Evidenciação Contábil das Informações Ambientais: uma análise das empresas da serra gaúcha listadas na bovespa. Revista rosa dos Ventos. ed 6., 2014. Disponível em: http://www.ucs.br/etc/revistas/index.php/ rosadosventos/article/view/2837o. Acesso em: 09 de junho de 2015.

JIA, L. et al. Study on Application of Computable General Equilibrium Mode in Water Resources Accounting. DEStech Transactions on Environment, Energy and Earth Sciences USA, 2017. Disponivel em: http://dpiproceedings.com/index. php/dteees/article/view/ 13312. Acesso em: 10 jun. 2018.

KASSAI, J. R. et al. Balanço contábil das nações: reflexões sobre os cenários de mudanças climáticas globais. BBR - Brazilian Business Review. ed. 9., $2012 . \quad$ Disponível em: http://www.bbronline.com.br/artigos.asp?sessao=ready \&cod_artigo $=196$. Acesso em: 04 jun. 2015.

MARCONI, P.; FERREIRA, T. S. Proposta de um sistema de captação de água de chuva no centro de juventude "Elaine Viviane". 2009. Monografia (Graduação em Engenharia Ambiental) - Escola de Engenharia de São Carlos, Universidade de São Paulo, 2009. Disponível em: <http://www.tcc.sc.usp.br/tce/disponiveis/18/ 180300/tce-22072010171018/> Acesso em: em 17 de junho, 2015.
MATTOS, R. Aplicação da contabilidade na gestão dos recursos hídricos. Dissertação (Mestrado em Engenharia da Energia) - Universidade Federal de Itajubá, 2003. Disponível em: http://saturno.unifei.edu.br/bim/0031114.pdf. Acesso em: 03 jun. 2015.

OMS, Organização Mundial de Saúde (2003). Domestic Water Quantity, Service Level and Health. Document WHO/SDE/WSH/03.02. Genebra: Organização Mundial da Saúde. Disponível em: https://www.who.int/water_sanitation_health/diseases/WSH03.02.pdf. Acesso em: 04 jun. 2015.

PAZ, A. R. da. Hidrografia Aplicada. Apostila aplicada no curso de graduação em Engenharia de Bioprocessos e Biotecnologia na unidade de Caxias do Sul. Paraíba, Universidade Federal da Paraíba, 2004. Disponível em: http://www.ct.ufpb .br/ adrianorpaz/artigos/apostila_ HIDROLO GIA_APLICADA_UERGS.pdf.. Acesso em: 10 jun. 2015.

PEREIRA; J. S.; KASSAI, J. R.; RAMOS, P. M. O. Balanço contábil dos recursos hídricos: um estudo de caso da região de Alagoinhas (BA). Revista Brasileira de Contabilidad,e ed. 16. Brasília: RCB, 2015. Disponível em: http://cfc.org.br/wp-content/uploads/2016/02/RBC216 _art2_abre_web.pdf. Acesso em: $30 \mathrm{dez} .2016$.

PHILIPPI, A. J. Saneamento, saúde e ambiente: fundamentos para um desenvolvimento sustentável. São Paulo: Manole, 2005.

RIBEIRO, M. DE S.; MARTINS, E. A Informação como instrumento de contribuição da contabilidade para a compatibilização no desenvolvimento no envolvimento econômico e a preservação do meio ambiente. Caderno de Estudos, FIPECAFI. 1993. Disponível em: http://www.scielo.br/scielo.php?script=sci_arttext\&pid=S141392511993000200005\&lng= en\&nrm=iso. Acesso em: 20 jun. 2015.

RICHEY, A. S. et al. Quantifying renewable groundwater stress with GRACE. Water Resources Research. AGU, 2015. Disponivel em:http://onlinelibrary.wiley. com/ doi/10.1002/ 2015WR017349/pdf DOI: 10.1002/2015WR017349. Acesso em: 20 jul. 2015

SÁ, A. L. Teoria da contabilidade. São Paulo: Atlas, 2010.

SANTOS, M. O. R. M. dos. O Impacto da cobrança pelo uso da água no comportamento do usuário. Tese de Doutorado em Ciências em Engenharia Civil, $\quad$ UFRJ, 2000.2 Disponível http://www.ceivap.org.br/downloads/9.pdf. Acesso em: 09 jul. 2015.

UNESCO. United Nations Educational Scientific and Cultural Organization. The United Nations World Water Development Report: Water for People, Water for Life, 2003. Disponível em: http://www.unesco.org/new/en/natural-sciences/environment/ water/wwap/ wwdr/wwdr1-2003/. Acesso em: 10 jun. 2015.

The united nations world water development report: Managing Water under Uncertainty and Risk, 2012. Disponível em: http://www.unesco.org/new

/en/naturalsciences/environment/water/wwap/wwdr/wwdr4-2012/.

Acesso em: 10 jun. 2015.

The united nations world water development report: Managing Water under Uncertainty and Risk, 2015. Disponível em: http://www.unesco.org/new/en/naturalsciences/environment/water/wwa p/wwdr/wwdr4-2012/. Acesso em: 10 jun. 2015. 